\title{
Reimbursement of pharmaceuticals: reference pricing versus health technology assessment
}

\author{
Michael Drummond · Bengt Jönsson • \\ Frans Rutten · Tom Stargardt
}

Received: 23 July 2009/ Accepted: 10 August 2010/Published online: 28 August 2010

(c) The Author(s) 2010. This article is published with open access at Springerlink.com

\begin{abstract}
Reference pricing and health technology assessment are policies commonly applied in order to obtain more value for money from pharmaceuticals. This study focussed on decisions about the initial price and reimbursement status of innovative drugs and discussed the consequences for market access and cost. Four countries were studied: Germany, The Netherlands, Sweden and the United Kingdom. These countries have operated one, or both, of the two policies at certain points in time, sometimes in parallel. Drugs in four groups were considered: cholesterol-lowering agents, insulin analogues, biologic drugs for rheumatoid arthritis and "atypical" drugs for schizophrenia. Compared with HTA, reference pricing is a relatively blunt instrument for obtaining value for money from pharmaceuticals. Thus, its role in making reimbursement decisions should be limited to drugs which are therapeutically equivalent. HTA is a superior strategy for obtaining value for money because it addresses not only price but also the appropriate indications for the use of the drug and the relation between additional value and additional costs. However, given the relatively higher costs of
\end{abstract}

\footnotetext{
M. Drummond ( $\square)$

Centre for Health Economics, Alcuin 'A' Block, University of York, Heslington, York YO10 5DD, UK

e-mail: md18@york.ac.uk

B. Jönsson

Stockholm School of Economics, Stockholm, Sweden

F. Rutten

Erasmus University Rotterdam, Rotterdam, The Netherlands

T. Stargardt

Institute of Health Economics and Health Care Management,

Helmholz Zentrum, Munich, Germany
}

conducting HTAs, the most efficient approach might be a combination of both policies.

Keywords Pharmaceuticals - Reimbursement . Cost-effectiveness analysis - Health policy

JEL Classification $\quad \mathrm{I} 10 \cdot \mathrm{I} 18$

\section{Introduction}

In most jurisdictions, obtaining value for money from use of pharmaceuticals is seen as an important policy objective, since it is important in maximising the health gain from the use of health care resources. A range of policies exists, including generic substitution, patient co-payments and price controls. Two policies have become more popular in recent years: reference pricing and health technology assessment.

Under reference pricing, drugs that are judged to be similar are 'clustered' and a single level of reimbursement (i.e. the reference price) set for the cluster, usually based on the price of the cheapest drug in the group or on some average of existing prices [14]. The manufacturers of the various drugs in the cluster are free to charge a price higher than the reference price, but this tends not to be the case because of the fear that patients may be deterred by the higher co-pay. Since this severely restricts the possibility to compete, in some cases, it may not be profitable to launch a new product on the market. Therefore, the incentive to the manufacturer is to set a price close to the reference price. Some reference pricing schemes only cluster drugs with the same chemical entity, but others, such as the schemes operating in The Netherlands and in Germany, cluster drugs which are deemed to be therapeutically equivalent. It is these latter schemes that are of interest in this paper. 
Under health technology assessment, reimbursement is granted if the incremental cost-effectiveness ratio, comparing the drug with other relevant alternatives, is within the acceptable range. Since the price of the drug is an important driver of the cost-effectiveness ratio, there is an incentive for the manufacturer to set a price that results in an acceptable cost-effectiveness ratio. Since a drug cannot be cost-effective in itself, but only in relation to a defined comparator and for a defined indication, HTA can be used to restrict reimbursement within the licensed indications [24].

In principle, both policies relate the value of the drug to its price but do so in slightly different ways. Normally, the assessments of comparability made under reference pricing are not as detailed as those made under technology assessment. The focus is on relative clinical effectiveness, defined fairly narrowly, rather than relative value. Also, health technology assessment is more flexible, since it allows the consideration of cost-effectiveness by indication (for example, first line or second line), or patient subgroup, whereas reference pricing sets a single reimbursement level for the drug in all its licensed indications.

On the other hand, health technology assessment, if performed correctly, can be very resource intensive. In addition, considerable time and effort may be consumed in demonstrating minor differences between products that, whilst being present, may not justify a difference in the amount reimbursed. In such cases, a simple clustering approach would be less resource intensive.

Several Western European countries have adopted one or other of these policies at various points in time. The ideal policy would be one that provides sufficient rewards (to manufacturers) for innovation, whilst securing value for money for the health care system. The objective of this paper is to compare and contrast reference pricing with health technology assessment, with a view to identifying the pros and cons of each.

\section{Methods}

The general approach was to focus on decisions about initial price and reimbursement status for innovative drugs. Four countries were considered: Germany, the Netherlands, Sweden and the United Kingdom. Germany has had a reference pricing system for many years, based on therapeutic equivalence. When being introduced in 1989, German reference pricing initially affected all pharmaceuticals-with or without patent protection. Later, patented, pharmaceuticals, with marketing authorisation subsequent to 1st January 1996, were excluded from reference pricing. This was partly revoked by an amendment in 2004. If a patented drug is considered a me-too drug and the respective original drug is already off-patent, both drugs are included in the reference pricing scheme [23]. A newly formed institute (IQWiG) is undertaking health technology assessments. From its formation in 2005, IQWiG's assessment of drugs was restricted to "benefit assessment", which can be interpreted as relative effectiveness. However, with the health reform act of 2007, the German legislator extended the scope of the IQWiG and is planning to introduce a reimbursement limit (i.e. a 'maximum price', linked to results from economic evaluations (i.e. health technology assessments) for drugs that are not subject to reference pricing.

The Netherlands has also operated a reference pricing system since 1991, based on therapeutic equivalence. In addition, health technology assessments are undertaken for drugs that are, a priori, considered to be sufficiently innovative to justify a premium price.

Sweden operated a reference pricing policy for drugs of chemical equivalence between 1993 and 2002. However, it was replaced by a drug substitution scheme, where the pharmacies select the available drug with the lowest price in the class. In the same year, the Pharmaceutical Benefit Board (LFN) was established. The LFN (now called the Dental and Pharmaceutical Benefits Agency-TLV) decides on the reimbursement of new drugs based on health technology assessments. The system is product oriented, but TLV can restrict reimbursement to specific indications or for a limited time whilst more data are collected. It also reviews groups of drugs defined by ATC code. The TLV also decides on which drugs are included in the generic substitution scheme and keeps a record of their prices.

The United Kingdom operates the health technology assessment policy, but does not operate reference pricing. In England and Wales, the National Institute for Health and Clinical Excellence (NICE) appraises those new drugs thought likely to have a major clinical or economic impact on the NHS. In Scotland, the Scottish Medicines Consortium (SMC) undertakes health technology assessments of all new drugs. The various technology appraisals undertaken in the United Kingdom vary in their cost and complexity. However, although the United Kingdom has no experience with reference pricing, it is included in this study since it provides an example of what can be achieved by the extensive use of HTA in decisions about drug reimbursement [7].

We considered innovative new drugs in four clinical areas, comparing and contrasting the outcomes (in price and reimbursement status) in the four countries. The areas considered were as follows:

1 hyperlipidaemia: where there are both new and existing statins, plus other new drugs for reducing lipid levels (e.g. ezetmibe); 
2 diabetes: where there are new insulin analogues and long-acting insulin;

3 rheumatoid arthritis: where there are several new biologic agents;

4 schizophrenia: where there are several new atypical neuroleptics.

These four disease areas were chosen primarily because they are quite important, yet quite diverse. Also, it was known that decisions on pricing and reimbursement had recently been taken in the four countries of interest, either through reference pricing or health technology assessment. Most drugs in these classes are also prescription drugs, which means that they are included in the reimbursement system. However, one of the rheumatoid arthritis drugs is a hospital product and hence not included in all cases. Ideally, it would be preferable to study drugs in all disease areas, but we have no reason to believe that the reimbursement issues relating to drugs in these 4 areas are atypical of those for drugs more generally.

\section{Results}

\section{Hyperlipidaemia}

In the four countries being studied, the older statins, including pravastatin and simvastatin, are now off-patent. Therefore, the analysis focussed on atorvastatin and two new cholesterol-lowering agents, rosuvastatin and ezetimibe. (Ezetimibe is available both as a single agent and in combination with simvastatin.)

\section{Prices}

Table 1 shows the current prices of the various drugs in the four countries, obtained from the following sources (http://www.medicijnkosten.nl, http://www.aponet.de
, http://www.ppa.org.uk, http://tlv.se). The prices quoted are those applying on 1st March 2008 and are ex-pharmacy prices, reflecting the full cost of the products to the health care system. Therefore, when comments are made below about the differences in prices between the four countries, these could reflect differences in pharmacy margins as well as differences in the amount received by the manufacturer in each case. Also, the cross-country price comparisons are dependent on the currency conversion rate used at the time of the study.

For statins, it can be seen that the prices of all the drugs are higher in Germany than the other three countries. However, because atorvastatin has been clustered with other statins under the reference price scheme (see below), the reimbursement level is much lower than the price. This implies that patients prescribed atorvastatin would face large co-payments or would have to switch to other statin agents. Rosuvastatin was not marketed in Germany at the time of the study. There could be many reasons for this, but it is likely that the low reference price for statins is a major factor in the company's decision not to launch. Ezetimibe is not clustered with any other drugs, being from a different class.

\section{Reimbursement status}

In Germany, statins, being one of the first four reference pricing groups formed after the amendment of 2004, are clustered in one reimbursement group including branded original drugs, their generic copies and patented drugs considered me-too (a so-called jumbo group). This decision was made based on a report by the Institute for Quality and Efficiency in Health Care (IQWiG), which did not find significant evidence for the superiority of atorvastatin over other statins in respect of efficacy or side-effect profile [10].

In the Netherlands, the statins are clustered, along with ezetimibe and ezetimibe/simvastatin. Although the prices
Table 1 Prices of cholesterollowering drugs $(€)$

Prices shown are off pharmacy prices. If the amount reimbursed is lower than the price, this is shown in parentheses. The patient pays the difference

N/A not available

a Exchange rate: SEK

$9.50=1 €$

${ }^{\mathrm{b}}$ Exchange rate: $£ 0.70=1 €$

c Combination treatment not available. Prices based on the individual drugs

\begin{tabular}{|c|c|c|c|c|}
\hline Agent & Germany & $\begin{array}{l}\text { The } \\
\text { Netherlands }\end{array}$ & Sweden $^{\mathrm{a}}$ & $\begin{array}{l}\text { United } \\
\text { Kingdom }^{\mathrm{b}}\end{array}$ \\
\hline Atorvastatin $10 \mathrm{mg}$ & $1.29(0.65)$ & 1.03 & 0.91 & 0.92 \\
\hline Atorvastatin $20 \mathrm{mg}$ & $1.84(0.81)$ & 1.47 & 1.33 & 1.26 \\
\hline Atorvastatin $40 \mathrm{mg}$ & $2.13(1.06)$ & 1.82 & 1.78 & 1.44 \\
\hline Ezetimibe $10 \mathrm{mg}$ & 1.88 & 1.54 & 1.26 & 1.34 \\
\hline Ezetimibe/simva 10/20 mg & 2.40 & 1.87 & $1.30^{\mathrm{c}}$ & 1.70 \\
\hline Ezetimibe/simva 10/40 mg & 2.73 & 2.15 & $1.39^{\mathrm{c}}$ & 1.99 \\
\hline Ezetimibe/simva 10/80 mg & 2.86 & 2.26 & $1.46^{\mathrm{c}}$ & 2.13 \\
\hline Rosuvastatin $5 \mathrm{mg}$ & N/A & 0.74 & 1.02 & 0.92 \\
\hline Rosuvastatin $10 \mathrm{mg}$ & N/A & 1.06 & 0.91 & 0.92 \\
\hline Rosuvastatin $20 \mathrm{mg}$ & N/A & 1.57 & 1.34 & 1.33 \\
\hline Rosuvastatin $40 \mathrm{mg}$ & N/A & 1.90 & 1.89 & 1.52 \\
\hline
\end{tabular}


of the drugs differ, the patient receives full reimbursement, which is an exception under reference pricing. Since 2005, health insurers are allowed to impose restrictions on the delivery of statins to their insured, and nowadays more than $70 \%$ of insured can only get reimbursement for the lowest priced generic unless the prescribing physician states that a higher priced statin must be delivered for medical reasons.

In Sweden, atorvastatin is generally available for treatment of hyperlipidaemia, since the reimbursement decision was made before the patent expired for simvastatin (Zocor). The use of both rosuvastatin and ezetimibe is restricted to patients who have tried generic simvastatin but for different reasons need another product. For example, ezetimibe is only reimbursed for patients where other treatment options are not available (e.g. where statins are not suitable) and as add-on therapy to statins in patients with inadequate control meeting the following criteria (established coronary artery disease, other atherosclerotic disease, type 2 diabetes, hereditary hypercholesterolaemia and multiple risk factors).

Prices for statins fell on average by $70 \%$ when the patent expired for simvastatin (Zocor) in February 2003. An indirect effect of this was that the sales of atorvastatin and pravastatin were reduced. It is thought that $10 \%$ points of the $70 \%$ average reduction in cost per daily defined dose (DDD) for statins were due to this indirect effect. The patent expiration probably also had a strong negative effect on the sales of rosuvastatin. By 2006, simvastatin had 85 per cent of the market in terms of volume (doses or patients treated) [8].

Recently, lipid-lowering medicines were the subject of a review conducted by the TLV. As a result of this, the branded versions of simvastatin and pravastatin lost their reimbursement status, as did branded atorvastatin $(10 \mathrm{mg}$ strength) and rosuvastatin (5 $\mathrm{mg}$ strength). Atorvastatin and rosuvastatin are reimbursed in other strengths only if generic simvastatin has been tried and the patient has not achieved the treatment objectives. Ezetimibe is reimbursed if generic simvastatin has been tried and the patient has not achieved the treatment objectives, or it has been established that the patient cannot tolerate statins [25].

In the United Kingdom, statin therapy was approved by NICE (in England and Wales) for primary prevention in adults with a $20 \%$ or greater 10 -year risk of CVD. However, therapy should usually be initiated with a drug with a low acquisition cost, taking account of the required daily dose [16]. In Scotland, the SMC approved rosuvastatin for general use, but restricted the use of ezetimibe and ezetimibe/simvastatin to patients who are unable to reach target levels of cholesterol, despite titration of their existing statin.

\section{Diabetes}

Until recently, the treatment of diabetes involved the use of insulin and oral antidiabetic drugs that have been on the market for several years. However, several new drugs have become available, particularly for the treatment of type 2 diabetes.

The focus here was on the insulin analogues (detemir, glulisine, lispro, aspart and glargine). Detemir and glulisine are long-acting formulations that provide a more consistent release during the day, thereby mimicking natural basal insulin release. The prolonged absorption profile, with no pronounced peaks over $24 \mathrm{~h}$, allows for once-daily dosing. Furthermore, since they do not require resuspension prior to administration, because of their soluble formulation, they have the potential to reduce inter-and intra-user variability.

Aspart, glulisine and lispro are rapid-acting analogues that mimic the physiological meal-time insulin profile much more closely than unmodified human insulin injections can. Peak plasma concentrations are reached about an hour after injection, with absorption finishing within 3-5 h. Accordingly, they control the rise in blood glucose concentrations better after meals, thereby reducing the risk of hypoglycaemia after food absorption has ceased.

\section{Prices}

Table 2 shows the current prices of the insulin analogues in the four countries. Again, the prices in Germany are higher than in the other countries. However, use of the new products has been restricted as the result of a technology assessment report.

\section{Reimbursement status}

In Germany, IQWiG undertook an assessment of rapidacting insulin analogues for the treatment of type 2 diabetes [9]. The literature search initially gave 1,017 hits, but these were reduced to 19 publications after further scrutiny by the reviewers. In the end, only seven studies were used in the assessment, as IQWiG decided to concentrate on randomised controlled trials only. In five of the studies, insulin lispro was compared with human insulin, and in the other two, insulin glulisine was compared with human insulin. In all cases, the drugs were added to basal long-acting insulin. No relevant study was published on insulin aspart.

All the clinical trials that met the inclusion criteria were over a relatively short period (5.5-12 months), which meant that they could not consider the effect of rapid-acting insulins analogues on diabetic complications or overall mortality. The analysis had a very narrow clinical focus, limited to assessments of hypoglycaemic rate and stability of the blood sugar level. There were only limited measurements of 
Table 2 Prices of insulin analogues $(€)$

Prices shown are off pharmacy prices. If the amount reimbursed is lower than the price, this is shown in parentheses. The patient pays the difference

${ }^{\text {a }}$ Exchange rate: SEK

$9.50=1 €$

b Exchange rate: $£ 0.70=1 €$

\begin{tabular}{llccc}
\hline Agent & Germany & $\begin{array}{l}\text { The } \\
\text { Netherlands }\end{array}$ & Sweden $^{\text {a }}$ & $\begin{array}{l}\text { United } \\
\text { Kingdom }^{\mathrm{b}}\end{array}$ \\
\hline Glulisine inj. 100 E/ml patron 3 ml & 13.82 & 7.17 & 8.19 & 8.42 \\
Glulisine inj. 100 E/ml WWSP 3 ml & 13.82 & 7.89 & 8.19 & 9.01 \\
Insulin lispro 100 E/ml patron 3 ml & 13.83 & 7.17 & 7.76 & 8.42 \\
Insulin lispro 100 E/ml WWSP 3 ml & 14.22 & 7.89 & 8.70 & 8.42 \\
Detemir penfill inj. 100 E/ml patron 3 ml & 15.77 & 11.85 & 12.80 & 11.15 \\
Detemir penfill inj. 100 E/ml WWSP 3 ml & 16.12 & 12.37 & 13.11 & 11.15 \\
Glargine inj. 100 E/ml patron 3 ml & 17.26 & 11.85 & 12.80 & 11.15 \\
Glargine inj. 100 E/ml WWSP 3 ml & 17.62 & 12.37 & 13.11 & 12.01 \\
\hline
\end{tabular}

illness-related quality of life and none of patient satisfaction. Within the clinical trials included in the assessment, one would not expect much difference between the analogues and human insulin. Indeed, no differences were found. The question is whether there are important and relevant differences in patient satisfaction, quality of life and convenience of use that were not examined in the study.

Based on the report, the rapid-acting insulin analogues aspart, glulisine and lispro were excluded from reimbursement by the Federal Joint Committee (G-BA) for patients with diabetes mellitus type 2 , as long as cost of treatment with an rapid-acting insulin analogue was more expensive than cost of treatment with human insulin. Exceptions were made for diabetes type 2 patients that are allergic to human insulin and for patients that could not be treated adequately with human insulin. Manufacturers reacted by offering large rebates to the sickness funds, whilst keeping the retail prices above the threshold. As the IQWiG assessment of long-acting insulins analogues has not been finished yet, no reimbursement limit has been set for determir and glargine.

In the Netherlands, insulin detemir and glargine are in one cluster and are of equal price. Insulin aspart and lispro are in another cluster, with a lower price. In both cases, the manufacturers have set the price equal to the reference price, so there are no patient co-payments.

In Sweden, both the rapid-acting insulin analogues, glulisine and lispro, are reimbursed without restrictions. The long-acting insulin glargine is also reimbursed without restrictions, but determir is reimbursed only for patients with type 1 diabetes. Insulins are excluded from the normal co-payment system in Sweden, as they are medications for a chronic disease. Co-payment is linked to total drug expenditures during a 12-month period and involves a deductable and coinsurance. Maximum co-pay is 200 Euro for a 12-month period, which means that most patients on chronic medications have "free drugs".

In the United Kingdom, insulin glargine was considered by NICE (for England and Wales). It was recommended as a treatment option for people with type 1 diabetes. However, the Institute considered that the cost-effectiveness of insulin glargine was less well established for people with type 2 diabetes, principally because of the lower frequency of hypoglycaemic episodes among this group and consequently the relatively limited scope for improvement. Therefore, it recommended that insulin glargine should be considered only for those people with type 2 diabetes who (1) require assistance from a carer or health care professional to administer their insulin injections, (2) find their lifestyle is significantly restricted by recurrent symptomatic hypoglycaemic episodes or (3) would otherwise need twice-daily basal insulin injections in combination with oral antidiabetic drugs [17].

In Scotland, insulins detemir and glargine have been assessed by the SMC. Insulin detemir was accepted for restricted use, targeted on patients attempting to achieve better hypoglycaemic control. Insulin glargine was also accepted for restricted use, targeted on patients who are at risk or experience unacceptable frequency and/or severity of nocturnal hypoglycaemia on attempting to achieve better hypoglycaemic control during treatment with established insulins. It was also considered acceptable as a once-daily insulin for patients who require carer administration of their insulin. Routine use in type 2 diabetes was not supported for either insulin detemir or insulin glargine.

Rheumatoid arthritis

After many years with no new therapies, there have been several new drugs for RA in the last few years. This analysis focussed on the first TNF alpha blockers adalimumab, etanercept and infliximab. All the three are indicated when the patient has failed two or more DMARDs (diseasemodifying arthritis drugs), one of which should be methotrexate. In the case of infliximab, the drug should be used in addition to methotrexate. The TNF alpha blockers represent a breakthrough in therapy for many patients but are expensive. 


\section{Prices}

Table 3 shows the prices for the TNF alpha blockers in the four countries. Prices for all three drugs are substantially higher in Germany. In the Netherlands, infliximab is not included in the reference pricing scheme as it is a hospitalbased product. In this case, health insurers reimburse $80 \%$ of the costs of a specific list of very expensive hospital drugs, leaving only $20 \%$ to be paid out of the hospital budget. However, this regime is conditional on the monitoring of the performance (i.e. cost-effectiveness) of these drugs in practice. Continuation of the additional financing depends on the results of this monitoring after 3 years [2].

\section{Reimbursement status}

In Germany, there is no reimbursement limit for these drugs, as reference pricing does not include patented innovations and the amendments made to drug regulation policy in 2007 have not been implemented yet. Only if the first active ingredient of a potential group of drugs loses patent protection, a reference group will be formed. However, other regulatory instruments e.g. physician drug budgets and co-payments may influence price setting of manufacturers indirectly [3].

In the Netherlands, adalimumab and etanercept are in the same cluster and can be used according to licensed indications. Infliximab is not in the cluster since, being delivered by intravenous infusion, it is a hospital-based product. Patients can receive this drug without co-payment at the hospital. Adalimumab and etanercept are reimbursed without major restrictions. Sweden has among the highest use of TNF inhibitors in Europe, comparable only to Norway. The use is more than twice as high as in Germany $[12,13]$.

In the United Kingdom, all three drugs have been reviewed by NICE. Although there were some small differences in the estimated cost-effectiveness of the different agents, the conclusion of the appraisal was that all drugs could be used in line with their licensed indications. No additional restrictions were initially applied, although a revision of the guidance in October 2007 stated that treatment should only be continued if there is an adequate response at 6 months following initiation of therapy [19].

\section{Atypicals for schizophrenia}

In recent years, several new drugs have become available for the treatment of schizophrenia. Although technically belonging to different classes, they go under the common term 'atypicals'. These drugs include risperidone, olanzapine, quetiapine and aripiprazole. Although not particularly expensive for a course of therapy, they are a much higher price than drugs that have been available for many years, such as haloperidol.

\section{Prices}

Table 4 shows the prices of the various drugs in the four countries. The prices are fairly similar for The Netherlands, Sweden and the United Kingdom, but higher for Germany.

\section{Reimbursement status}

In Germany, there is no reimbursement limit for any of these drugs. In the Netherlands, all atypicals are in the same cluster. Prices are fairly similar, so patient co-payments are minor. In Sweden, all the drugs are reimbursed without restrictions. In the United Kingdom, NICE reviewed the first three atypicals: quetiapine, olanzapine and risperidone. Whilst noting that there were differences in the range of evidence for the different products, it did not distinguish between them. It recommended the use of all atypicals first line [18].

In Scotland, the SMC allowed general use of aripiprazole. It has not reported on the use of the other atypicals, but use of the drugs is in line with the NICE recommendations. In addition, both NICE and the SMC have considered the use of the atypicals in related conditions, such as bipolar disorder.

Table 3 Prices of TNF $\alpha$ Blockers $(€)$

\begin{tabular}{|c|c|c|c|c|}
\hline Agent & Germany & $\begin{array}{l}\text { The } \\
\text { Netherlands }\end{array}$ & Sweden $^{\mathrm{a}}$ & $\begin{array}{l}\text { United } \\
\text { Kingdom }\end{array}$ \\
\hline Adalimumab inj $40 \mathrm{mg} / \mathrm{ml}$ or $50 \mathrm{mg} / \mathrm{ml} \mathrm{WWSP} 0.8 \mathrm{ml}$ & 960 & 576 & 604 & 511 \\
\hline Etanercept 50 inj. mg/ml WWSP $1.0 \mathrm{ml}$ & 456 & 288 & 302 & 226 \\
\hline Infliximab $100 \mathrm{mg}$ & 868 & N/A & 574 & 600 \\
\hline
\end{tabular}

Prices shown are off pharmacy prices. If the amount reimbursed differs, this is shown in parentheses. The patient pays the difference

N/A not available

${ }^{\mathrm{a}}$ Exchange rate: $9.50=1 €$

${ }^{\mathrm{b}}$ Exchange rate: $£ 0.70=1 €$ 
Table 4 Prices of atypicals for schizophrenia

Prices shown are off pharmacy prices. If the amount reimbursed is lower than the price, this is shown in parentheses

${ }^{\text {a }}$ Exchange rate: SEK

$9.50=1 €$

b Exchange rate: $£ 0.70=1 €$

\begin{tabular}{llllc}
\hline Agent & Germany & $\begin{array}{l}\text { The } \\
\text { Netherlands }\end{array}$ & Sweden & $\begin{array}{l}\text { United } \\
\text { Kingdom }^{\mathrm{b}}\end{array}$ \\
\hline Risperidone $1 \mathrm{mg}$ & 2.12 & 0.99 & 0.84 & 0.82 \\
Risperidone $2 \mathrm{mg}$ & 3.55 & 1.77 & 1.58 & 1.63 \\
Olanzapine $2.5 \mathrm{mg}$ & 3.14 & 1.78 & 1.87 & 1.70 \\
Olanzapine $5 \mathrm{mg}$ & 4.53 & 2.17 & 2.73 & 2.46 \\
Quetiapine $25 \mathrm{mg}$ & 1.44 & 0.74 & 0.72 & 0.82 \\
Quetiapine $100 \mathrm{mg}$ & 2.37 & 1.52 & 1.37 & 2.69 \\
Quetiapine $200 \mathrm{mg}$ & 3.89 & 2.54 & 2.09 & 2.69 \\
Aripiprazole $15 \mathrm{mg}$ & 8.73 & 4.18 & 4.51 & 5.05 \\
Aripiprazole $30 \mathrm{mg}$ & 13.88 & 8.38 & 8.36 & 10.38 \\
\hline
\end{tabular}

\section{Discussion}

The main advantage of reference pricing is that it is relatively easy to implement on a comprehensive basis, covering all new and existing drugs. (Our focus here was on its application to new drugs.) It is also probably less costly to administer than health technology assessment, although an evaluation in Norway, undertaken prior to the abandonment of the policy, showed that the costs outweighed the savings [12]. Also, behind the Norwegian decision to replace reference pricing with generic substitution was an evaluation that the system was complicated to administer and did not produce significant gains after the initial price reductions. Experience shows that, in general, the policy is effective in forcing prices down to the reference price, but manufacturers have no incentives for further price reductions, or to consider which indications for their drug would be most cost-effective.

However, the main issues with reference pricing relate to how it is applied in practice. Beyond its use for drugs containing the same molecule, the key question is that of how similar do different drugs have to be in order to be clustered and what level of analysis precedes clustering? Also, in the absence of health technology assessment, what method should be used to set the reference price for a new cluster? (In The Netherlands, the price is set relative to the price in other countries).

In addition, under reference pricing, all the licensed indications for a drug are tacitly accepted, whereas it may be more cost-effective in certain indications, or for particular patient subgroups. Finally, setting reference prices for some drugs might lead to price increase for drugs not subject to reference pricing.

In principle, health technology assessment allows a consideration of all the costs and benefits of innovative drugs in a wide range of indications and patient subgroups. It is also more flexible. For example, recommendations can be revised as more evidence becomes available, or reimbursement can be made conditional on the gathering of additional data. In addition, value for money is explicitly addressed, and decision-makers can set their threshold of willingness-to-pay for innovation.

The main problems with health technology assessment relate to the difficulties of implementing the policy on a comprehensive basis and the difficulties of conducting appraisals of sufficient quality. In particular, if every new drug were to be assessed for cost-effectiveness, in many settings this assessment would be, of necessity, very cursory, since the resources would not be available to undertake all the assessments thoroughly. Therefore, it may make sense to prioritise the assessments towards those innovative compounds that are the first in their class. Then, if similar drugs are launched at a similar price, it probably does not make sense to undertake a thorough assessment.

A natural experiment is taking place in the United Kingdom with respect to the thoroughness of health technology assessments. In Scotland, the procedure is not very resource-intensive and, as a consequence, every new drug can be considered. In England and Wales, the standard assessments undertaken by NICE (called Multiple Technology Assessments or MTAs) are very detailed, but the recently introduced single technology appraisals (STAs) are closer to the Scottish model. Both models incorporate a submission, of a technology assessment, by the manufacturer. The main difference surrounds the detail of the independent evaluation of the evidence on effectiveness and cost-effectiveness. Therefore, a subsidiary question is whether different types of appraisals give rise to different decisions. This is beginning to be studied the general conclusion being that the broader decisions, about whether a given drug is recommended for use, are fairly similar. However, some of the more detailed decisions, about the indications for use of the drug, or the most suitable patient populations, sometimes differ $[1,4]$.

A related issue is that of whether the decision-making body provides funding for an independent group to undertake the assessment. In the Netherlands and Sweden, the evaluation is undertaken by the Health Care Insurance 
Board (CvZ) and TLV, respectively. In Germany, the assessments are undertaken by IQWiG. In the United Kingdom, both NICE and the SMC commission an external assessment. Clearly, in all systems much depends on the quality of the manufacturer's submission and the rigour of the evaluation.

The ways in which health technology assessment is applied vary from place to place. The approaches to health technology assessment in the United Kingdom largely follow the methodological guidelines laid down by NICE [20], which encourage the use of decision-analytic modelling. However, in Germany, IQWiG's initial methods guidance placed a major emphasis on the clinical evidence obtained from randomised controlled trials [6]. However, subsequent versions of the guidance have suggested an expanded role for modelling [11]. This begs the question as to whether there could be more harmonisation of the methods of health technology assessment in Europe [22].

Any impact of reference pricing and health technology assessment on value for money will be apparent in the observed price and reimbursement status of the various drug groups in the four countries. With respect to pricing, the impact of reference pricing is only substantial when there are wide differences in the prices of drugs in a given cluster. Since the focus of this paper was on the initial price of innovative drugs, wide differences were not generally observed, since the manufacturers of similar drugs tend to price them at a similar level in a given market. However, as was seen in Germany, as soon as one of the drugs in the cluster becomes generic, reference pricing can have a major impact. Normally, one would expect the price of all drugs in the cluster to fall to the level of the reference price. However, in the case of the drug groups studied here, the manufacturers maintained their original price. In the case of atorvastatin, this led to increased patient co-payments; in the case of insulin analogues, the price was maintained by use of a subsidy.

The precise impact of health technology assessment on prices is hard to assess, and no clear pattern could be observed in the cross-country price differences reported in this paper. In theory, one would expect the manufacturer to propose a price that will result in the drug being costeffective when it is subjected to an HTA. It is not normal for the HTA to be a vehicle for price negotiation in most countries, although there are examples of manufacturers offering deals that amount to price reductions as part of the discussions surrounding the HTA. Many of these discussions do not reach the public domain, the payment by results scheme for bortezomib (Velcade) in the United Kingdom being an example of one that did [21].

With respect to reimbursement, the focus of reference pricing is on establishing the reimbursement level for the cluster. As mentioned earlier, in the absence of a generic, or otherwise inexpensive drug, it is unclear how this level is set. On the other hand, the flexibility that exists under the policy of health technology assessment, where reimbursement can be conditional or limited to certain indications or patient subgroups, is clearly very important in the quest to secure more value for money. Most of the recommendations following health technology assessments do not result in straightforward acceptance or rejection of the new drug. Rather, they mostly limit the use of the drug to the indications or patients in which it is most cost-effective. Many of the recommendations of bodies like NICE point to the need for future research [15]. Therefore, the recommendations following HTAs potentially reward innovation, whilst paying attention to value for money. This may become even more apparent if value-based pricing schemes, such as that proposed in the United Kingdom, are implemented. Under such schemes, the price of a drug would be based on the value it adds in each individual indication, as demonstrated through technology appraisals [5].

\section{Conclusions}

Reference pricing alone does not represent a viable policy for obtaining value for money from pharmaceuticals. Health technology assessment represents a much better approach, for the reasons discussed earlier. In particular, it incorporates an explicit assessment of the value for money of new drugs, in various indications and patient subgroups.

Reference pricing may have a supporting role, since it provides an approach for making decisions about the pricing and reimbursement of those drugs which are therapeutically equivalent to other, existing drugs, and for which it would be a waste of resources to conduct a health technology assessment. However, it is not the only such policy. Encouragement of price competition and generic substitution would be others. A combination of reference pricing and price competition was introduced in Germany in 2006. Drugs priced below 30 per cent of the reference price are exempted from regular co-payments. It was expected that this would trigger price competition and enable the regulator to set lower reference prices in return. However, long-term effects of the policy change have not yet been evaluated.

It could be that a dual policy is emerging, whereby the primary policy for obtaining value for money from new drugs is based on health technology assessment, supported by reference pricing or another approach. A good example would be the situation in The Netherlands, where innovative drugs are subjected to health technology assessment, in order to assess whether they should be placed in a new cluster and to establish the reference price for any new 
cluster. Germany is also heading in this direction, as it introduced maximum reimbursement prices for drugs that are not subject to reference pricing based on HTA.

Acknowledgments The study was funded by an unrestricted grant from the Schering Plough Corporation. All views expressed are those of the authors alone.

Open Access This article is distributed under the terms of the Creative Commons Attribution Noncommercial License which permits any noncommercial use, distribution, and reproduction in any medium, provided the original author(s) and source are credited.

\section{References}

1. Barbieri, M., Hawkins, N., Sculpher, M.: Who does the numbers? The role of third-party technology assessment to inform health systems' decision-making about the funding of health technologies. Value Health. (2008) Epub ahead of print

2. Brouwer, W., Rutten, F.: The Netherlands. In: Rapoport, J., Jacobs, P., Jonsson, E. (eds.) Cost Containment and Efficiency in National Health Systems: A Global Comparison. Wiley, Weinheim (2009)

3. Busse, R., Schreyogg, J., Henke, K.-D.: Pharmaceutical regulation in Germany: Improving efficiency and controlling expenditures. Int. J. Health Plan. Manag. 20, 329-349 (2005)

4. Cairns, J.: Providing guidance to the NHS: The Scottish medicines consortium and the National Institute for clinical excellence compared. Health Policy 76, 134-143 (2006)

5. Claxton, K.: OFT, VBP; QED? Health Econ. 16, 545-558 (2007)

6. Drummond, M.F., Rutten, F.F.H.: New Methodological Guidelines in England and Germany: Are We Any Closer to Agreeing International Standards. Office for Health Economics, London (2008)

7. Drummond, M.F., Sorenson, C.: Use of pharmacoeconomics in drug reimbursement in Australia, Canada and the United Kingdom: what can we learn from international experience? In: Arnold, R.G. (ed.) Pharmacoeconomics From Theory to Practice. CRC Press, Boca Raton USA (2009)

8. Engström, A., Jacob, J., Lundin, D.: Sharp drop in prices after introduction of generic substitution. LFN (now TLV), http://www. tlv.se (2006). Accessed 13 Mar 2009

9. IQWiG: Rapid-Acting Insulin Analogues for the Treatment of Diabetes Mellitus Type 2. Institute for Quality and Efficiency in Health Care (IQWiG), Koeln (2006)
10. IQWiG: Nutzenbewertung der Statine unter Besonderer Beruecksichtigung von Atorvastatin. Institute for Quality and Efficiency in Health Care (IQWiG), Koeln (2005)

11. IQWiG: General Methods 3.0. Institute for Quality and Efficiency in Health Care (IQWiG), Koeln (2008)

12. Jönsson, B.: Reference pricing: central economic and policy issues. In: López-Casasnovas, G., Jönsson, B. (eds.) Reference Pricing and Pharmaceutical Policy, pp. 80-85. Springer, Barcelona (2001)

13. Jönsson, B., Kobelt, G., Smolen, J.: The burden of rheumatoid arthritis and access to treatment: Uptake of new therapies. Eur. J. Health Econ. (Suppl. 2), S61-S86 (2008)

14. López-Casasnovas, G., Jönsson, B. (eds.): Reference Pricing and Pharmaceutical Policy, pp. 80-85. Springer, Barcelona (2001)

15. Mason, A., Drummond, M.F., Towse, A.: Economic Post-Launch Studies: Matching the Desirable With the Feasible. Office of Health Economics, London (2006)

16. National Institute for Health and Clinical Excellence: Statins for the Prevention of Cardiovascular Events. Technology Appraisal 94. NICE, London (2006)

17. National Institute for Health and Clinical Excellence: Guidance on the Use of Long-Acting Insulin Analogues for the Treatment of Diabetes-Insulin Glargine. Technology Appraisal 53. NICE, London (2002)

18. National Institute for Health and Clinical Excellence: Schizophrenia-Atypical Antipsychotics. Technology Appraisal 43. NICE, London (2002)

19. National Institute for Health and Clinical Excellence: Adalimumab, Etanercept and Infiximab for the Treatment of Rheumatoid Arthritis. Technology Appraisal 130. NICE, London (2007)

20. National Institute for Health and Clinical Excellence: Guide to the Methods of Technology Appraisal. NICE, London (2007)

21. National Institute for Health and Clinical Excellence: Multiple Myeloma-Bortezomib. Technology Appraisal 129. NICE, London (2007)

22. Sculpher, M.J., Drummond, M.F.: Analysis sans frontiers: Can we ever make economic evaluations generalisable across jurisdictions? PharmacoEconomics. 24, 1087-1099 (2006)

23. Stargardt, T., Schreyögg, J., Busse, R.: Arzneimittelfestbetraege: gruppenbildung, preisberechnung mittels regressionsverfahren und wirkungen. Das Gesundheitswesen. 67, 468-477 (2005)

24. Taylor, R.S., Drummond, M.F., Salkeld, G., Sullivan, S.D.: Chapter 5: Development of fourth hurdle policies around the world. In: Freemantle, N., Hill, S. (eds.) Evaluating pharmaceuticals for health policy and reimbursement. BMJ Books, London (2004)

25. TLV.: Review of drugs for lipid disorders. http://www.tlv.se (2009). Accessed 22 Feb 2009 